\title{
A ÍNDIA MUNDURUCU CAROLINA ROSALINA DE OLIVEIRA E SEUS LIDERADOS NA LUTA CONTRA O ESBULHO DE SEU TERRITÓRIO ÉTNICO: O CONFLITO DO RIO ATININGA, MANICORÉ/AM (1955)
}

\author{
THE MUNDURUCU INDIA CAROLINA ROSALINA DE OLIVEIRA AND ITS \\ LEADERS IN THE FIGHT AGAINST THE OUTLINES OF ITS ETHNIC \\ TERRITORY: THE CONFLICT OF THE ATININGA RIVER, MANICORÉ / \\ AM (1955)

\section{Davi Avelino Leal ${ }^{1}$ Dário Duarte Araújo²}

\begin{abstract}
Resumo
O artigo recupera os conflitos envolvendo os moradores do lugar Alegria, no rio Atininga (Manicoré), liderados pela índia Mundurucu Carolina Rosalina de Oliveira, contra o esbulho e a intrusão dos territórios étnicos praticados pelos patrões Raimundo Avelino, Antonio Avelino e Hélio Rego. Pela dimensão e gravidade do conflito, acabou sendo bem documentado pelos jornais de grande circulação do Estado e pelo Serviço de Proteção aos Índios, o SPI, revelando uma intensa disputa discursiva sobre o ocorrido e seus desdobramentos. Nesse episódio, duas visões contrastantes estavam em jogo: de um lado, uma baseada em uma economia predatória voltada para o mercado internacional e concentrada na extração e beneficiamento da castanha e de outros recursos, do outro, uma visão em que o modo de vida construído pela busca da dignidade constitui-se no principal valor pelo qual se luta.
\end{abstract}

Palavras-chave: Conflito; território; etnicidade.

\begin{abstract}
The article recovers the conflicts involving the residents of the place Alegria, on the Atininga river (Manicoré), led by the Indian Mundurucu Carolina Rosalina de Oliveira, against the debris and intrusion of the ethnic territories practiced by the bosses Raimundo Avelino, Antonio Avelino and Hélio Rego. Due to the dimension and gravity of the conflict, it ended up being well documented by the newspapers of great circulation in the State and by the Indian Protection Service, the SPI, revealing an intense discursive dispute about what happened and its consequences. In this episode, two contrasting views were at stake: on the one hand, one based on a predatory economy aimed at the international market and focused on the extraction and processing of nuts and other resources, on the other, a view in which the way of life built the search for dignity is the main value for which we fight.
\end{abstract}

Keywords: Conflict; territory; ethnicity.

\footnotetext{
${ }^{1}$ Doutor em Sociedade e Cultura na Amazônia (UFAM). Professor do Departamento de História da Universidade Federal do Amazonas. E-mail: davileal81@ gmail.com

${ }^{2}$ Especialista em História e Cultura pela Universidade Cândido Mendes (UCAM) e Licenciado em História pela Universidade Federal de Rondônia (UNIR). Professor de História da rede municipal de Manaus. Email: dario_alibi@hotmail.com
} 


\section{Introdução}

A crise da economia da borracha ${ }^{3}$ não significou, de forma alguma, a decadência do extrativismo na Amazônia ${ }^{4}$. Determinadas áreas, como Manicoré ${ }^{5}$ e Borba, no rio Madeira, intensificaram a retirada de outros produtos da floresta ou do rio. A coleta da castanha se tornou a principal atividade econômica da região ${ }^{6}$, gerando novos processos de mobilização da força de trabalho e de conflitos sociais envolvendo comerciantes que atuavam tanto nos rios como regatões quanto aviando mercadorias nos barracões e que passaram a intrusar e esbulhar áreas tradicionalmente ocupadas ${ }^{7}$ por "beiradeiros", pequenos produtores e povos indígenas. Reeditavam-se as tensões e antagonismos sociais vividos no processo de expansão da fronteira gomífera do século $\mathrm{XIX}^{8}$, só que a partir de então em ambiente de retração econômica.

A conjuntura vivida nas décadas de 1930 e 1940 foi marcada por essa dinâmica de retorno às diversas formas de extrativismos, aliadas à permanência de relações de exploração das populações locais que, por sua vez, buscavam reconquistar espaços de autonomia e fortalecimento de suas atividades tradicionais na várzea, nos rios e nas florestas. O famoso acordo de Washington, assinado em 1942 entre Brasil e Estados Unidos para fornecimento de matéria prima e insumos no contexto da Segunda Guerra Mundial, não foi capaz de alavancar as atividades gumíferas em toda região amazônica, concentrando-se sobretudo no rio Tapajós. Foi nesse contexto que outras atividades

\footnotetext{
${ }^{3}$ De acordo com a historiografia sobre o tema, a partir de 1912 a economia amazônica baseada na extração da goma elástica adentra uma longa crise por conta da concorrência da produção inglesa na Ásia, o que acarretou na desvalorização do preço da borracha extraída da Amazônia. WEINSTEIN, Bárbara. A Borracha na Amazônia: expansão e decadência (1850-1920). São Paulo: Hucitec - USP, 1993.

${ }^{4}$ PRAIA, Benta Litaiff. A crise da economia gomífera e o mundo do trabalho em Manaus (1910-1930). Dissertação de Mestrado em História, Programa de Pós-Graduação em História. Universidade Federal do Amazonas, 2010; LEAL, Davi Avelino Leal. Direitos e Processos Diferenciados de Territorialização: os conflitos pelo uso dos recursos naturais no rio Madeira (1861-1932). Tese de Doutorado, Programa de Pós-Graduação Sociedade e Cultura na Amazônia. Universidade Federal do Amazonas, 2013.

${ }^{5}$ Município situado ao sul do Estado do Amazonas, à margem direita do Rio Madeira, entre os rios Atininga, que fica a montante, e Mataurá, a jusante. SCHNETZER, Paul. Manicoré(AM). Boletim do Conselho Nacional de Estatística, Coleção Monografias. B, n.97. Brasília, 1961.

${ }^{6}$ De acordo com Paul Schnetzer, pesquisador do Conselho Nacional de Estatística (CNE), órgão ligado ao Instituto Brasileiro de Geografia e Estatística (IBGE), as principais atividades econômicas do município no início da década de 1960 eram: colheita da castanha-do-pará, extração de seringa, sorva, copaíba, pau-rosa, peixes e animais silvestres, além das roças e lavouras dos moradores. SCHNETZER, Paul. Manicoré(AM). Boletim do Conselho Nacional de Estatística, Coleção Monografias. B, n.97. Brasília, 1961.

${ }^{7} \mathrm{O}$ conceito de territórios tradicionalmente ocupados pode ser encontrado em ALMEIDA, Alfredo Wagner Berno de. Terras Tradicionalmente Ocupadas: "terras de quilombo", "terras indígenas", "babaçuais livres", "castanhais do povo", "faxinais" e "fundos de pasto". 2 ed. Manaus: PNCA-UFAM, 2008.

${ }^{8}$ LEAL, Davi Avelino. Entre Barracões, Varadouros e Tapiris: os seringueiros e as relações de poder nos seringais do rio Madeira (1880-1930).Dissertação de Mestrado, Programa de Pós-Graduação em Sociedade e Cultura na Amazônia. Universidade Federal do Amazonas, 2007.
} 
extrativistas passaram a ser exploradas e que os conflitos agrários, sobretudo em áreas de castanhais, passaram a se intensificar. O caso do rio Antiga ${ }^{9}$, em Manicoré, envolvendo um grupo de pessoas que ocupavam tradicionalmente as terras e que tinham a índia Munduruku Carolina Rosalina de Oliveira como sua liderança contra o comerciante (regatão e dono de barracão) Raimundo Avelino, conhecido como "Dico"Avelino, ultrapassou as fronteiras locais e ganhou uma dimensão regional.

\section{O Conflito do rio Atininga, Manicoré(1955)}

As tensões e conflitos em toda região do rio Madeira não eram novidade no final da década de 1940 e início de $1950^{10}$. Ao desmantelamento dos seringais, repassados como espólio da crise para grandes firmas aviadoras de Manaus ${ }^{11}$ ou transformados em bairros populares ${ }^{12}$ nas décadas de 1920 e 1930, seguiram-se movimentos de intrusão de territórios indígenas ricos em castanhais, que passaram a ser alvo de comerciantes da área. A documentação compulsada para o que ocorreu no rio Atininga, afluente do rio Madeira, no município de Manicoré, evidencia as múltiplas dimensões desse contexto conflitivo.

\section{Imagem 01 - Rio Atininga, município de Manicoré, rio Madeira (AM)}

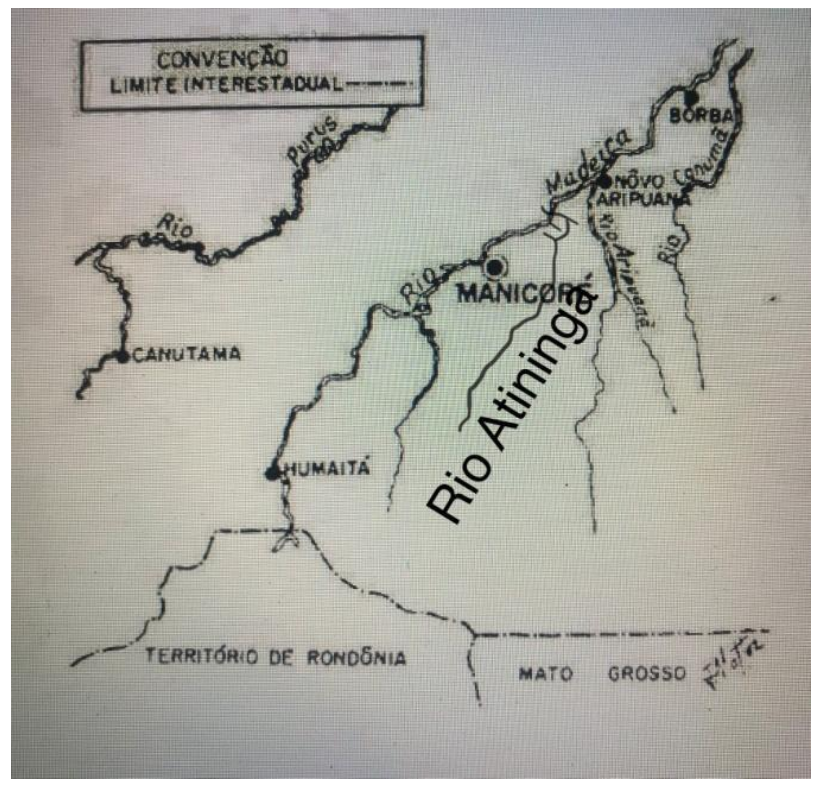

Fonte: Boletim do Conselho Nacional de Estatística, Coleção Monografias. B, n.97. Brasília, 1961.

\footnotetext{
${ }^{9}$ Rio de águas escuras que passa por trás da sede do município de Manicoré. Muito Frequentado por seus balneários e por pescadores.

${ }^{10}$ MELO, Joaquim. SPI: A Política Indigenista na Amazônia. Manaus: Edições do Governo do Estado, 2009.

11 BENCHIMOL, Samuel. Manaus - Memória Empresarial. Manaus: Governo do Estado do Amazonas/Universidade do Amazonas/Associação Comercial, 1994.

12 COSTA, Luciane Marinho. Política e Territorialidade: as transformações sociais com a criação dos projetos de assentamento agroextrativistas em Humaitá (Am). 2010. Dissertação( Mestrado em Sociedade e Cultura). Instituto de Ciências Humanas e Letras, Universidade Federal do Amazonas, Manaus, 2010
} 
Em 1954, o vespertino Diário da Tarde ${ }^{13}$ publicou em sua edição de número 5.796 longa matéria assinada pelo repórter Bento de Oliveira sobre o esbulho das terras indígenas pertencentes aos moradores do rio Atininga, praticado por Raimundo Avelino da Rocha ${ }^{14}$. Na ocasião, a liderança indígena Carolina Rosalina de Oliveira viera a Manaus, junto com alguns moradores, denunciar Raimundo Avelino ao Serviço de Proteção aos Índios (SPI) ${ }^{15}$ pelo esbulho, intrusão e todo tipo de violência praticada contra os moradores do lugar Alegria.

\section{Imagem 2 - Carolina Rosalina de Oliveira e seus companheiros em visita ao inspetor do SPI}

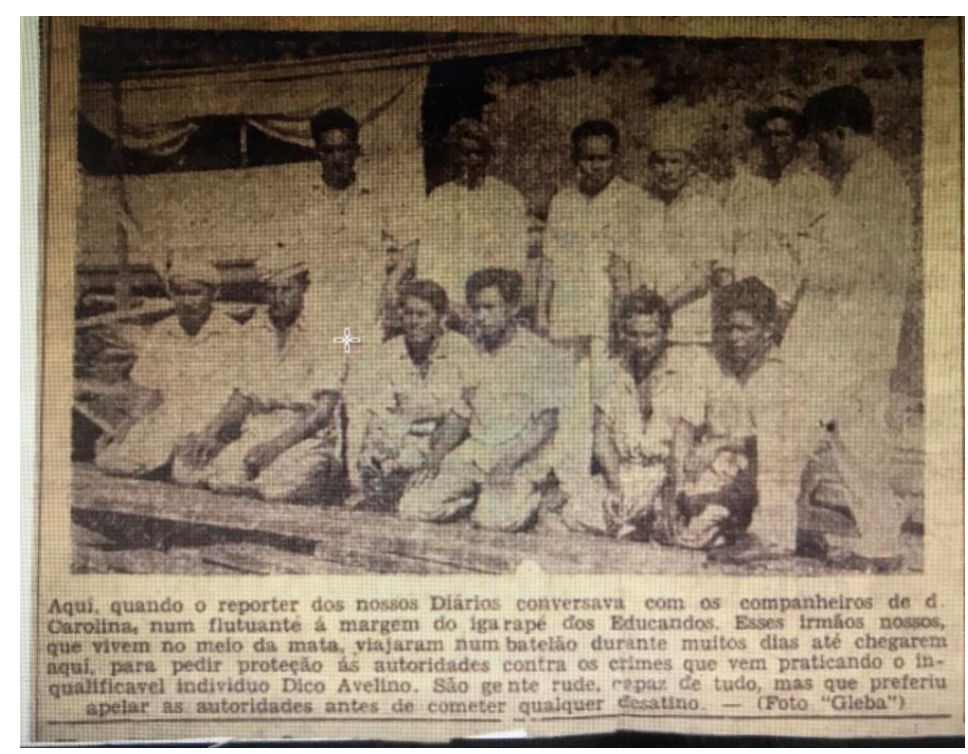

Fonte: Diário da Tarde, 20 de dezembro de 1954. Acervo: Museu do Índio. Cx 56/Plan. 389

Conforme documentação produzida pelo SPI, as tensões envolvendo a firma Avelino \& Irmãos já eram conhecidas pela agência indigenista, pois um ofício enviado no dia 3 de janeiro de 1955 pelo chefe da inspetoria regional Alípio Edmundo Lage aos

\footnotetext{
${ }^{13}$ Diário da Tarde, 20 de dezembro de 1954. N. 5796.

${ }^{14}$ Raimundo Avelino da Rocha era juntamente com seu irmão Antônio Avelino da Rocha e seu genro Hélio de Oliveira Rego Sócio da firma Avelino \& Irmãos. Fonte: Ofício enviado por Alípio Edmundo Lage ao diretor do Serviço de Proteção aos Índios, situado no Rio de Janeiro. Manaus, 27 de setembro de 1956.

${ }^{15}$ Criado em 1910 como Serviço de Proteção aos Índios e Localização dos Trabalhadores Nacionais (SPILTN) e conhecido apenas como SPI ou Serviço, foi a principal agência do estadobrasileiro a aplicar a política indigenista entre 1910-1967. Dentre seus objetivos estava a busca pela integração dos povos indígenas na condição de trabalhadores nacionais. LIMA, Antonio Carlos de Souza. Um grande cerco de paz: poder tutelar, indianidade e formação do Estado no Brasil. Petrópolis: RJ, Vozes, 1995.
} 
seus superiores informa que Raimundo Avelino vem se apossando indevidamente de grandes castanhais pertencentes aos índios de segunda ${ }^{16}$ e terceira categorias da região ${ }^{17}$.

Ainda segundo o relato do inspetor, no dia 02 de agosto de 1954 um oficial de justiça visitou a comunidade Alegria e intimou os índios para se apresentarem ao juiz da comarca para fazer a defesa do uso da área. Tal ação teria sido ignorada pelos moradores, o que motivou a Raimundo e Antônio Avelino irem com um oficial de justiça e mais alguns capangas e prenderem 39 moradores, jogando-os no porão de um motor da propriedade da firma Avelino \& Irmãos para serem levados e processados na comarca de Manicoré. Com a insistência dos índios em permanecerem na comunidade, mesmo após o incidente de agosto, Raimundo Avelino retorna ao aldeamento, prende e leva mais 20 pessoas para a sede do município. Desses, 15 conseguem fugir e vêm a Manaus fazer a denúncia para o jornal do Diário da Tarde.

A odisseia se deu em um batelão que saiu de Manicoré e depois de alguns dias aportou nas margens do igarapé do Educandos, local em que Bento de Oliveira conversou com a liderança indígena. A narrativa de dona Carolina revelou a truculência com que agia Raimundo Avelino, destruindo as roças e impedindo que os moradores do lugar continuassem a retirar castanhas, borracha e outros produtos da floresta. Com o aumento da tensão e a escalada da violência, "Dico" Avelino passou a colocar os moradores que desrespeitavam as suas normas no interior de canoas e batelões e os deixava em comunidades distantes.

Por conta dessas ações, motivadas inclusive pelo fato de Raimundo Avelino ter conseguido documentos e testemunhos que "indicavam" que desde os anos 1920 grandes extensões de terras do rio Atininga pertenciam a sua família e que tais documentos foram reconhecidos pelo juiz da comarca de Manicoré, foi que os moradores decidiram fugir da ação de Avelino e irem até Manaus. Ao chegar, Carolina de Oliveira reclama que o comerciante Raimundo Avelino vinha esbulhando o seu direito de propriedade no rio Atininga e que seus companheiros Mura vinham tendo um tratamento desumano por parte dos civilizados ${ }^{18}$.

\footnotetext{
${ }^{16}$ De acordo com a classificação estabelecida pelo SPI os índios de segunda categoria, ou segunda classe, eram aqueles que já contatados de forma violenta pelos ditos civilizados. Já os de terceira categoria são os índios que vivem em aldeamentos e postos do SPI, próximo às vilas dos "civilizados"e que mantêm relações de comércio e outras trocas. LIMA, Antonio Carlos de Souza. Um grande cerco de paz: poder tutelar, indianidade e formação do Estado no Brasil. Petrópolis: RJ, Vozes, 1995.

${ }^{17}$ Arquivo do Museu do Índio, RJ. Ofício enviado por Alípio Edmundo Lage ao diretor do Serviço de Proteção aos Índios, situado no Rio de Janeiro. Manaus, 03 de janeiro de 1955.

${ }^{18}$ Diário da Tarde, 20 de dezembro de 1954.
} 


\section{Imagem 3 - Carolina Rosalina de Oliveira e sua família em visita ao inspetor do SPI}

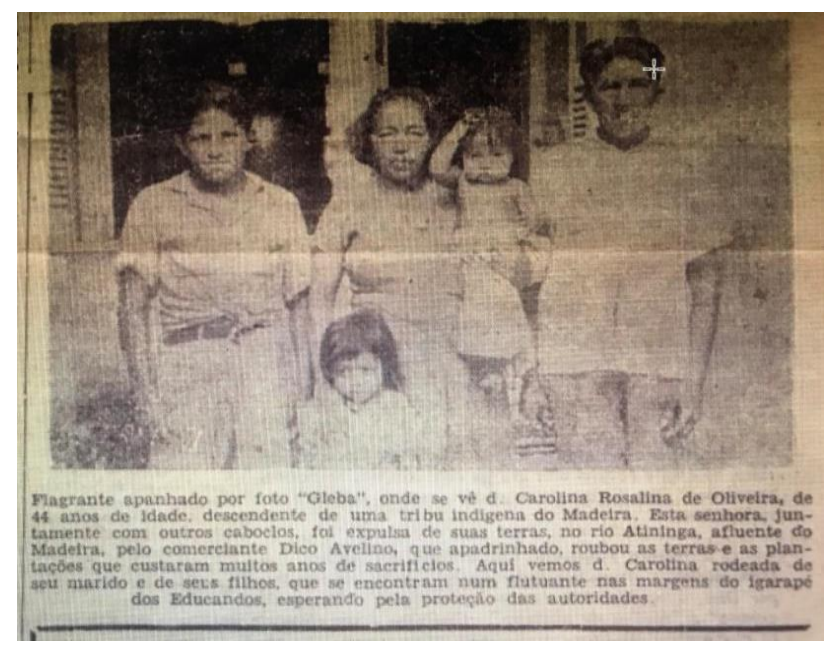

Fonte: Diário da Tarde, 20 de dezembro de 1954. Acervo: Museu do Índio. Cx 56/Plan. 389

Embora tenha ocupado página inteira do Diário da Tarde, aparentemente o esforço da viagem não surtiu o efeito esperado, pois no dia 9 de junho de 1955, explode um conflito armado envolvendo moradores do lugar Alegria e forças policiais de Manicoré, que teriam ido expulsar trabalhadores a mando de Raimundo Avelino. O estopim para o conflito se deu por conta de um dos sócios de Raimundo Avelino, o comerciante Hélio Rêgo, ter contratado um rapaz para limpar uma estrada de castanha nos lugares já tradicionalmente ocupados pelos moradores do lugar Alegria. A atitude foi vista como provocação e o empregado foi expulso. Hélio Rêgo solicitou que a guarda municipal fosse ao lugar e retirasse à força os moradores. Teria ocorrido então um confronto armado em que os moradores, liderados por Carolina Oliveira, expulsaram também os militares, resultando em três agentes feridos ${ }^{19}$.

O conflito ganha as páginas da imprensa na cidade de Manaus. O Jornal do Comércio de 12 de junho de $1955^{20}$ noticia que uma mulher comandava 500 bandoleiros no rio Atininga e que o governo do Estado deveria enviar uma força para debelar os revoltosos. No dia 13 de junho é a vez do jornal $A$ Crítica ${ }^{21}$ sair com a notícia assinada pelo comerciante e repórter Genaro Massulo sobre o ocorrido.

\footnotetext{
${ }^{19}$ Jornal A Critica, 13 de junho de 1955, p.03.

${ }^{20}$ Jornal do Commercio, 12 de junho de 1955.

${ }^{21}$ Jornal A Crítica, 13 de junho de 1955, p.03.
} 


\section{A ORDEM ERA MATAR. REPORTAGEM DE GENARO MASSULO. Chegaram os Feridos Do Tiroteio De "ATININGA".}

Por questões de terras, mais um conflito se verificou em Manicoré. Desta vez foi palco o castanhal "Atininga", invadido por 50 bandoleiros que obedecem ao comando de D. Carolina de Oliveira. Uma caravana policial, ao ir fazer uma diligência naquela localidade, foi recebida a bala, oferecendo um balanço de três feridos.

\section{ANTECEDENTES}

Há vários anos, existe uma luta tradicional entre vários capitães de castanhais e o Sr. Dico Avelino, (que se diz proprietário de "Atininga"), sendo desta vez, ao que parece um conflito mais sério porque do lado oposto está a respeitável figura de D. Carolina de Oliveira.

\section{QUEM É A TEMÍVEL MULHER}

D. Carolina de Oliveira, é uma piauiense que, vez por outra visita sede de Manicoré e dado o seu desassombro e valentia é temida até pelas mais grandes autoridades. Mulher que apresenta mais de quarenta anos de idade. Já veio a Manaus, por três vezes em uma canoa, o que evidencia sua bravura. Depois de desmoralizar vários delegados de polícia, resolve agora chefiar um bando de 50 caboclos, bem municiados e fazer com que Dico Avelino e seus sócios debandem de uma vez para sempre do castanhal "Atininga".

\section{COMO SE DEU O FATO.}

Hélio Rêgo um dos sócios do referido castanhal, contratou um rapaz para fazer uma limpeza em um "pico" na propriedade em tela. Foi a esta altura que Domingos Barroso, um dos Generais do bando, procurou o rapaz da limpeza e deu um prazo para que ele se retirasse da região $\mathrm{O}$ mais urgente possível, pois, caso contrário o seu cadáver ficaria sepultado em "Atininga".

\section{COMUNICADA A POLÍCIA.}

O contratado de Hélio Rêgo ao chegar na sede do Município queixouse à delegacia de Polícia. Sem perda de tempo o Delegado Tota Leite organizou diligência composta dos guardas municipais João Ferreira Ramos, João Soares e do Comerciante Genaro Massulo (sócio de "Atininga", elemento bastante conhecido em nossa capital e cunhado de nosso confrade Newton Aguiar).

\section{A OCORRÊNCIA}

No dia 9 do corrente, às 16 horas e 30 minutos chegou viajando em uma lancha, a caravana policial. Mal parava a lancha já os caravaneiros eram alvo das balas que partiam de uma moita. Genaro e o delegado conseguiram se esconder atrás da embarcação enquanto os guardas João Ferreira Ramos e João Soares eram atingidos pelas balas. Os bandoleiros de D. Carolina fizeram uma pausa e Genaro com muita perícia conseguiu dar atrás com a embarcação, fugindo assim aos furiosos assassinos. 
A reportagem do jornal A Crítica, mesmo tendendo para uma versão em que culpabilizava os moradores do lugar Alegria, permite recuperar a dimensão do conflito de terra e a posição de liderança ocupada por Carolina Rosalina de Oliveira em antagonismo com os comerciantes e proprietários "Dico"Avelino e Hélio Rêgo.

Como o caso explodiu na imprensa da capital, Manaus, os holofotes se voltaram para o rio Atininga. Tanto o governador Plínio Ramos Coelho quanto o Serviço de Proteção Índio passaram a acompanhar de perto a situação. O líder do executivo ordenou que uma tropa de policiais militares fosse enviada em um avião Catalina para a cidade de Manicoré. A expedição punitiva fora acompanhada pelo repórter do jornal A Crítica Aron Ypiranga Benevides, que expôs nas páginas do jornal seu ponto de vista.

Ao iniciar essa reportagem, quero antes de tudo expressar aqui os agradecimentos do repórter a todos que contribuíram para o êxito da missão árdua e espinhosa como só e ser a do homem de imprensa que alimenta um único desejo: o de trazer ao conhecimento do público, a narração dos fatos com a maior sensação de ânimo e com a máxima honestidade de propósito.

Ao ter conhecimento das ocorrências que estavam se verificando no rio Atininga, procuramos conseguir duas vagas no avião que deveria conduzir o destacamento da força policial comandada pelo segundo Tenente Alcides e mais os sargentos Francisco Moreira e Onézio Paiva, 4 cabos e treze praças para por fim invasão das terras de propriedade da firma Raimundo Avelino \& Irmãos, cujos títulos tivemos a oportunidade de verificar no cartório com a anuência do Juiz de direito daquela comarca dos seguintes castanhais. Barreirinha e São Francisco, expedido em 29 de Agosto de 1927, Tabocal e Paulista em 9 de abril de 1931 e registrados no cartório de ofício daquela comarca sob os números, 312,313,314 e 417, todos situados no Rio Atininga e que estava sendo invadido por uns bandoleiros chefiados por uma mulher de nome Carolina Rosalina de Oliveira.

De saída, o jornalista já chama os moradores dos lugares citados no rio Atininga de invasores de propriedade particular e bandoleiros armados, mencionando inclusive os títulos passados em cartório do município de Manicoré. O tom estigmatizante e acusatório da narrativa perpassa toda a matéria publicada no jornal. Ao falar da chegada das tropas em Manicoré, o repórter faz questão de mencionar que:

Enorme multidão se aglomerava no barranco para ver a força que iria por termo a violência e o saque e restabelecer a ordem já tão grandemente ameaçada pela ação dos bandoleiros chefiados por uma mulher, que apesar de analfabeta, já havia conseguido com conversa e com outros meios aliciar elementos para expulsar trabalhadores da colheita de castanhas e arruinar a vida de diversos homens, os quais devido a ignorância da região com cerca de noventa por cento de analfabetos, foram arrastados ao crime e suas famílias entregues a própria sorte. 
Neste momento emerge da fala do enviado de A Crítica o reconhecimento de que uma mulher liderava o grupo de bandoleiros e que juntos resistiam, expulsando quem adentrasse as estradas de castanhas do grupo. No entanto, o repórter atacou mais uma vez o grupo descaracterizando o aspecto étnico do qual muitos faziam parte ao dizer que naquela área não havia indígenas.

\section{UMA FARÇA A EXISTÊNCIA DE INDIOS NO RIO ATININGA.}

Pouco a pouco fomos tomando contato com os poucos moradores que ainda se mantinham no local, em que uns tinham abandonados suas casas por terem tomado parte no ataque a diligencia policial vinda de Manicoré e os outros que não tinha se envolvido haviam fugido em virtude do terror dos homens de Carolina. Aí fomos sabendo com e de que vivia a dirigente do bando. Apesar de analfabeta, ela exerce uma certa influencia em grande parte dos habitantes daquela região, fazendo viagens a Manaus, e dizendo que o inspetor do Serviço de Proteção aos Índios lhe dera ordens para que reagisse para que ninguém ali trabalhasse pois ela já havia registrado todos como índios e como tal ela garantia a permanência deles ali. Todos que fizesse parte de uma coligação por ela idealizada eram obrigados a fornecer tudo o que fosse necessário a sua subsistência como fosse: fazer roça, fornecer farinha, peixe e tudo o mais que ela precisasse inclusive dinheiro para suas viagens a Manaus.

Um outro meio usado por Carolina, segundo nos contaram, era insinuar os seus homens a ter relações amorosas com ela, marcando para tal um dia do mês para que assim fosse dominando mais os seus apaziguados. Um outro morador contou-nos que certa vez quando fora intimada a ir prestar declarações na delegacia de Policia de Manicoré e não tendo recursos para dar alimentação a seus capangas, vendo que os mesmos já começavam a se pacientar chamou para um lugar ermo e distante o satisfez a todos com o seu corpo num total de quarenta e seis homens.

Dizer-se que no rio atininga existe índio é como se estivesse faltando com a verdade dos fatos. Ali não encontramos sequer um para que contássemos se realmente existia índio naquela região. Os habitantes do rio atininga, na sua maioria são maranhenses, rio-grandenses do norte e alguns cearenses. De vestígios de índios somente encontramos preso na casa onde estivera Carolina três flechas enfiadas nas palhas e escrito a carvão na parede o seguinte: Este sítio é de propriedade do SPI.

Assim vive Carolina naquelas paragens a explorar a boa fé daqueles que acreditando em suas promessas satisfazendo os seus apetites vandalescos, dizendo que o inspetor dos índios determinara que ela impedisse a limpeza dos piques e que quando as terras lhe fossem dadas seriam distribuídas com aqueles que lhe obedece se conseguindo por esses meios viver como parasitas sem nada fazer e trazendo em sobressalto aqueles pobres que ali vive a lutar pelo pão de cada dia.

Esse trecho do relato do jornalista Aron Benevides revela não apenas um conjunto de estereótipos com relação aos moradores do Atininga ${ }^{22}$, mas mostra também as

\footnotetext{
${ }^{22}$ Muitos pertencentes a povos indígenas e outros a migrantes ou descendentes de grupos oriundos do nordeste brasileiro que não se identificavam como pertencente a determinados grupos étnicos.
} 
intencionalidades de criminalizar a existência do outro, sobretudo de grupos subalternizados que se levantavam contra as forças do latifúndio na região. Lida a contrapelo, a passagem permite observar as formas de agenciamento acionadas por Carolina Oliveira ao recorrer à agência indigenista e sua força política representada pelo SPI. Antes de ter estourado o conflito, Carolina Oliveira já estivera pelo menos três vezes em Manaus para conferenciar e se articular com Alípio Lage, que na ocasião ocupava o papel de chefe da primeira inspetoria regional do SPI.

Ao negar o reconhecimento da identidade étnica dos moradores do rio Atininga, o jornalista buscava também deslegitimar a luta e o direito aos territórios étnicos assegurados aos índios desde os tempos coloniais ou dos períodos de demarcação estabelecidos pela agência indigenista nas primeiras décadas do século XX. Neste caso específico, o discurso jornalístico atua na defesa dos interesses dos patrões, contrastando com o ponto de vista apresentado pelo repórter do Diário da Tarde, Bento de Oliveira.

Esse jogo discursivo que busca classificar e enquadrar os sujeitos sociais revelase vacilante e permeado de contradições, o que possibilita adentrar e ler as diversas camadas de sentido atribuídas pelos agentes sociais em jogo. Um exemplo instigante disso, que fora mencionado acima, pode ser encontrado no jornal A Crítica de 13 de junho de 1955. Ali, Carolina Rosalina de Oliveira é identificada como uma piauiense, descendente de índios Mundurucu. Mulher destemida, valente, forte e respeitada pelas autoridades locais ${ }^{23}$, imagem oposta à definida por Aron Benevides. Nesse caso, o estabelecimento da identidade étnica de Carolina de Oliveira ultrapassa fronteiras previamente definidas, revelando-se em toda a sua complexidade.

Após as diligências para captura dos envolvidos no confronto com os agentes da guarda municipal, nãofoipossívelencontrar Carolina Rosalina, que se embrenhounamata com osseus para fugir da repressãopolicial, vindo a se entregar para a polícia dias depois na cidade de Manaus. Sobre esse momento, o Jornal do Commercio ${ }^{24}$ destacou a seguinte matéria:

\section{Carolina conta a verdadeira epopeia vivida no Rio Madeira.}

Todo o bando do Atininga entregou-se á polícia depois de acossada pela força.

Narrativa impressionante de uma pobre mulher que apenas clama por justiça - acusa os policiais de haverem investido contra os caboclos indefesos - A história de uma mãe que adora a sua filhinha.

\footnotetext{
${ }^{23}$ Jornal A Crítica, 13 de junho de 1955.

${ }^{24}$ Jornal do Commercio, 22 de junho de 1955. p.1
} 
Está mais ou menos esclarecido o caso do Rio Atininga, no Município de Manicoré, que vinha prendendo a atenção das autoridades responsáveis pelo Estado, principalmente dos que estão a frente do Departamento Estadual de Segurança Pública. Mais luzes já pairam sobre o assunto, e isso por ter chegado a Manaus, ontem, a celebre Dona Carolina de Oliveira, que era tida como chefe do movimento de rebeldia que se estalara em uma localidade marginal daquele curso d'água.

Veio ela acompanhada de sete caboclos, a maioria de idade um pouco avançada, pertencentes ao seu tão falado bando e de condição humilde e pobre como ela. Carolina trouxe ainda uma filhinha sua não a deixando no Atininga em virtude de sua tenra idade e da necessidade que ela tem de amamentá-la.

Os homens que vieram com Carolina foram devidamente identificados, sendo depois recolhidos depois ao xadrez. Ela, no entanto não passou por tal coisa, tendo sido apenas detida em uma dependência da Delegacia de Segurança Policial. Fomos encontrála à tarde de ontem em companhia de sua filha e de outra senhora de nome Aurora de tal. Conversamos demoradamente com dona Carolina e tivemos pela sua palavra de cabocla humilde uma versão dos acontecimentos completamente diferente daquela que propalara. As lágrimas the marejaram os olhos causando nos pena, quando nos relatava o que na verdade aconteceu.

Realmente parece que houve um intuito inescrupuloso e desumano ao se imputar a Carolina de Oliveira a responsabilidade pelos distúrbios e pelos incidentes, incidentes até de caráter grave, que se registraram no rio Atininga. Chegou-se a dizer que ela estava pondo em polvorosa todos os moradores daquele rio, promovendo tudo isso com a conivência e com o auxilio de cerca de cem homens, todos bem armados e municiados. Isso, no entanto, jamais aconteceu, não passando de invencionice criminosa de um latifundiário madeirense que atende pelo nome de Hélio Rego. Dona Carolina e seus companheiros de misérias foram vitimas do espírito mesquinho desse cidadão.

Não coube a dona Carolina, conforme ela mesmo depõe, a culpa nem a iniciativa do ataque à bala, a caravana policial que esteve em Atininga. Pelo contrario: foram os policiais que fizeram essa investida violenta contra os pobres caboclos, a estes apenas e podendo dizer que revidaram o ataque, numa pura e legítima defesa. Tudo o que se disse, portanto, a respeito dos acontecimentos não teve outro propósito senão desalojar daquelas terras dona Carolina e seus companheiros.

São terras que lhes não pertencem de direito, mas que, de fato, são suas, pois ali nasceram cresceram e vivem. Elas as terras, lhes pertencem pela tradição e pela grandeza que lhes são inatas (grifo nosso).

Por esses fatos e por essas circunstancias, faz se necessário que as autoridades amazonenses inclusive as que estão tratando do caso, procurem estudar com espírito de justiça e humanidade os fatos que tornaram celebre a cabocla Carolina de Oliveira. Não é justo que ela, por não ter quem a defenda e quem lute pelos seus direitos, venha a ser responsabilizada e castigada por crimes que não cometeu. Sua situação de serva da terra, da qual tira o necessário para a sua sobrevivência e a sobrevivência dos seus, deve ser respeitada e 
olhada com atenção pelas nossas autoridades. Inconcebível a nosso ver, incriminá-la pelos fatos que tiveram lugar no Atininga. $\mathrm{O}$ assunto deve ser estudado e apreciado devidamente. E é preciso que seja chamado a Polícia, para prestar declarações, esse senhor que se chama Helio e a quem Carolina joga toda a responsabilidade pelos incidentes. Deve ele também vir a Manaus, e, ser recolhido ao xadrez, como foram os caboclos companheiros de dona Carolina.

Aqui emerge a versão de Carolina Rosalina de Oliveira, filtrada pela narrativa feita pelo repórter do jornal do comércio. Nela, a líder Mundurucu relata, amamentando sua filhinha de pouca idade, as artimanhas do madeirense latifundiário Hélio Rêgo para incriminar os moradores das localidades do rio Atininga. Conforme Carolina de Oliveira, ela e seus vizinhos apenas revidaram o ataque perpetrado pelos policiais da guarda, em um movimento de legítima defesa. O objetivo dos comerciantes era desalojar dona Carolina de Oliveira e seus companheiros daquele território que desde muito tempo estavam estabelecidos. Como dito na matéria: São terras que lhes não pertencem de direito, mas que, de fato, são suas, pois ali nasceram cresceram e vivem. Elas, as terras, lhes pertencem pela tradição e pela grandeza que lhes são inatas.

O desdobramento desse processo se deu com uma breve detenção de Carolina Rosalina de Oliveira na Delegacia de Segurança Policial e uma condenação de 18 meses para os 7 companheiros que vieram com ela para Manaus. Carolina de Oliveira não parou por aí. Buscou apoio junto à inspetoria do SPI para resolver a situação e retornar com os seus para o Atininga.

Em 1955, antes mesmo do conflito ter estourado, o SPI enviou o inspetor Francisco Meireiles para averiguar as tensões na área. Ele saiu de Manaus com o discurso de que o direito dos índios deveria ser preservado, prometendo defender as terras dos silvícolas por entender ser um direito líquido e certo ${ }^{25}$. Ao retornar, o discurso mudou. Passou a dizer nos jornais que não existiam mais índios em Manicoré e que aquelas pessoas que se diziam indígenas eram apenas descendentes de índios.

Tal versão, por sua vez, não convenceu ao chefe da inspetoria regional IR da 1a. região, Alípio Lage, que mandou Meireles realizar novas apurações sobre se de fato as propriedades estavam no nome de Raimundo Avelino, com ele alegava. O resultado dessa diligência foi que Raimundo Avelino apresentou documentação, títulos definitivos, que comprovariam ter comprado, em 1925, os lugares "Terra Preta", "Barreirinha", "São Francisco", "Tabocal" e "Paulista", todos situados no rio Atininga.

\footnotetext{
${ }^{25}$ Ofício enviado pelo Chefe da inspetoria do Amazonas Alípio Edmundo Lage ao diretor do Serviço de Proteção aos Índios do Rio de Janeiro.
} 
Diante desse resultado não esperado, Edmundo Lage propôs aos índios que se mudassem para o posto Jatapú, pois lá teriam terreno para agricultura, áreas para caça e rios piscosos. Ao comerciante Raimundo Avelino, pediu que pagasse uma quantia a título de indenização pelos prejuízos causados aos índios. Após a anuência de Avelino, que se comprometeu a pagar cinquenta mil cruzeiros a Carolina, esta, por sua vez, recusou-se a aceitar não apenas a quantia, mas também a reconhecer que aquelas terras pertenciam a Raimundo Avelino.

Inconformada com tal decisão, Carolina Rosalina de Oliveira resolveu escrever para o presidente Juscelino Kubitscheck, que na ocasião estava de passagem por Manaus. $\mathrm{Na} \operatorname{carta}^{26}$, Carolina diz que a sede de justiça foi o que a motivou a tomar tal atitude e suas súplicas serão atendidas pelo presidente. Ela inicia afirmando que possuía ascendência indígena e que seus antepassados já viviam no Atininga desde muito tempo e que a vida se desenrolava tranquilamente quando apareceu por lá o senhor Raimundo Avelino, necessitado e desamparado. Tal situação comoveu a comunidade e como bons brasileiros o acolhemos e ajudamos em tudo o que foi possível, porém esse senhor, com o passar do tempo, tornou-se o maior inimigo da comunidade, tendo usurpado da confiança nele depositada pelos moradores ao representá-los em um processo de legalização das terras em Manaus. Como sabia ler e escrever, Raimundo Avelino foi escolhido para tomar a frente desse processo, no entanto, ao retornar da missão, os moradores descobriram que ele teria requerido junto ao governo do Estado se colocando como único dono de todas as terras do rio Atininga, deixando desamparados os antigos moradores do lugar. Carolina de Oliveira ressalta que como indígena não estava acostumada a ser escravizada por outro e que a comunidade tinha decidido reivindicar, o que despertou ira de Avelino, que por sua vez passou a acusar Carolina e seus companheiros de roubar castanhas de suas propriedades. O resultado dessa disputa, segundo a autora, foi que 18 de seus companheiros foram presos, tendo que pagar pena de 1 ano e 8 meses em Manaus. Ela relata ao doutor Juscelino que mesmo que eles tivessem tirado castanha das estradas de Avelino, o castigo tinha sido desproporcional, pois o senhor Hélio Rêgo, genro de Raimundo Avelino, usara de violência física, espancando e martirizando os corpos dos moradores, gerando grande sofrimento ao seus companheiros. Ela intercede junto ao presidente para que suas terras sejam restituídas e seu martírio acabe e todos possam viver como os seus antepassados. Carolina Rosalina

\footnotetext{
${ }^{26}$ Carta ao Exmo. O Sr. O Dr. Juscelino K. De Oliveira. 1956. Arquivo do Museu do Índio. BRRJMISPIIR1- 666- 389- 61 - páginas 643 e 644.
} 
de Oliveira finaliza o texto lembrando que Raimundo Avelino ficara rico às custas do trabalho e da pobreza dos moradores indígenas daquele rio e pede para que as intermináveis perseguições cessem. Suas últimas palavras no texto são: Aguardo Dr. Juscelino a valiosa proteção de Vossa Excelência e ajoelhada imploro piedade para o meu sofrimento e dos meus irmãos de infortúnio. Da mais humilde e sofredora das brasileiras, a índia Carolina de Oliveira.

Esse valioso documento revela, a partir da fala de uma mulher indígena, uma trágica dimensão presente na história da Amazônia: a violência praticada contra os moradores dos rios, das várzeas e das florestas da região. Não são só os povos indígenas das mais diferentes etnias, mas também moradores dos beiradões que migraram do Rio Grande do Norte, Piauí, Maranhão e Ceará e que a despeito da propaganda de riqueza da floresta, nunca conseguiram se livrar da dívida imposta pelos patrões e toda carga de violências físicas e simbólicas praticadas por coronéis de barranco que se espalharam pelas calhas dos rios Amazônicos.

Mesmo diante de um quadro de adversidades, agravado pela crise econômica resultado da dêbacle da borracha, esses sujeitos sociais lutaram para construir um espaço de autonomia em que pudessem ter sua roça familiar, sua criação de galinhaouporco e tivessem acesso aos recursos agroflorestais nas épocas do ano propícias para isso. A crise da economia gomífera e a debandada de muitos patrões significou para vários desses grupos um afrouxamento das relações de trabalho e submissão, abrindo a possibilidade de luta e reivindicação sufocadas nos tempos de grande exploração no auge da extração da hévea.

Trata-se, portanto, de recuperar não apenas as formas de resistência presentes nos antagonismos sociais, mas de perceber as sutis estratégias de agenciamento acionadas pelos sujeitos sociais em situações de conflito. O conflito do rio Atininga revela a complexidade das alianças e os meandros que perpassam as experiências dos agentes sociais em luta. Tem-se como liderança dos indígenas, moradores dos territórios étnicos em que vivem e trabalham, uma mulher Munduruku. Em vários documentos consultados, ela reafirma sua identidade indígena e se coloca como liderança dos moradores, articulando junto à agência indigenista o apoio necessário para o enfrentamento do poder do latifúndio. A força e a audácia de Carolina Rosalina de Oliveira a leva a reivindicar o seu direito junto ao presidente da república, repetindo um movimento feito por várias lideranças indígenas ao longo da história do Brasil. 
Os motivos pelos quais ela lutou estão ali colocados, as formas de intrusão e esbulho recorrentes em toda a Amazônia estão ali explicitadas, assim como o apelo e a súplica a mais importante autoridade do país para que interceda ao seu favor aparece como última alternativa a ser tentada. O desfecho dessa história não encerra a força e o poder mobilizador que ela carrega. Carolina jamais pôde retornar a Manicoré para realizar o desejo de ser enterrada em Atininga. Seus filhos e filhas retornaram e hoje moram na cidade. Os seus companheiros de luta pagaram a pena e depois retornaram para a sede do município e recontaram essa história como forma de se fazer justiça à memória de Carolina.

\section{Considerações Finais}

O caso envolvendo as disputas por castanhais e seringais no rio Atininga não pode ser visto como um episódio isolado na Amazônia de meados do século XX. Essa dinâmica de conflitos e antagonismos em que a linguagem da violência é recorrente, está presente no cotidiano de centenas de comunidades espalhadas pelos rios da região. Não se trata apenas do controle dos recursos naturais, mas sobretudo da gestão do território, em que a mobilização e imobilização da força de trabalho dos moradores desses lugares ocupa um lugar central. Da parte dos moradores, indígenas ou não, as mais variadas formas de agenciamento e estratégias de resistência foram acionadas para garantir o uso dos territórios tradicionalmente ocupados. Nesse sentido, o conflito do Atininga revelou toda a complexidade desse movimento de intrusão, esbulho, denúncia e luta pela garantia da dignidade dos chamados"povostradicionais".

O que se desvela nesse caso é a existência de duas visões contrastantes que estão em jogo nessas disputas por esses territórios ricos em castanhais, seringais, lugares de roça, rios e lagos piscosos. Trata-se, de um lado, de uma visão baseada em uma economia predatória voltada para o mercado internacional e concentrada na extração e beneficiamento da castanha e de outros recursos, e do outro, uma visão em que o modo de vida construído pela busca da dignidade se constitui no principal valor pelo qual se luta.

Data de submissão: $25 / 08 / 2020$

Data de aceite: 16/02/2021 


\section{Referências Bibliográficas}

ALMEIDA, Alfredo Wagner Berno de. Terras Tradicionalmente Ocupadas: "terras de quilombo", "terras indígenas", "babaçuais livres", "castanhais do povo", "faxinais" e "fundos de pasto". 2 ed. Manaus: PNCA-UFAM, 2008.

BENCHIMOL, Samuel. Manaus - Memória Empresarial. Manaus: Governo do Estado do Amazonas/Universidade do Amazonas/Associação Comercial, 1994.

COSTA, Luciane Marinho. Política e Territorialidade: as transformações sociais com a criação dos projetos de assentamento agroextrativistas em Humaitá (Am). 2010. Dissertação( Mestrado em Sociedade e Cultura). Instituto de Ciências Humanas e Letras, Universidade Federal do Amazonas, Manaus, 2010

LEAL, Davi Avelino Leal. Direitos e Processos Diferenciados de Territorialização: os conflitos pelo uso dos recursos naturais no rio Madeira (1861-1932). Tese de Doutorado, Programa de Pós-Graduação Sociedade e Cultura na Amazônia. Universidade Federal do Amazonas, 2013.

LEAL, Davi Avelino. Entre Barracões, Varadouros e Tapiris: os seringueiros e as relações de poder nos seringais do rio Madeira (1880-1930).Dissertação de Mestrado, Programa de Pós-Graduação em Sociedade e Cultura na Amazônia. Universidade Federal do Amazonas, 2007.

LIMA, Antonio Carlos de Souza. Um grande cerco de paz: poder tutelar, indianidade e formação do Estado no Brasil. Petrópolis: RJ, Vozes, 1995.

MELO, Joaquim. SPI: A Política Indigenista na Amazônia. Manaus: Edições do Governo do Estado, 2009.

PRAIA, Benta Litaiff. A crise da economia gomífera e o mundo do trabalho em Manaus (1910-1930). Dissertação de Mestrado em História, Programa de Pós-Graduação em História. Universidade Federal do Amazonas, 2010.

SCHNETZER, Paul. Manicoré(AM). Boletim do Conselho Nacional de Estatística, Coleção Monografias. B, n.97. Brasília, 1961.

WEINSTEIN, Bárbara. A Borracha na Amazônia: expansão e decadência (1850-1920). São Paulo: Hucitec - USP, 1993. 